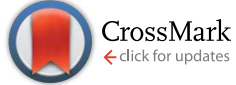

Cite this: Food Funct., 2014, 5, 1848

Received 12th March 2014

Accepted 3rd May 2014

DOI: $10.1039 / c 4 f o 00210 e$

www.rsc.org/foodfunction

\title{
Bioactivity and phytochemical characterization of Arenaria montana L.
}

\author{
Eliana Pereira,$\uparrow^{\mathrm{ab}}$ Lillian Barros, $\uparrow^{\mathrm{a}}$ Ricardo C. Calhelha, ${ }^{\text {ac }}$ Montserrat Dueñas, ${ }^{\mathrm{b}}$ \\ Ana Maria Carvalho, ${ }^{a}$ Celestino Santos-Buelga ${ }^{* b}$ and Isabel C. F. R. Ferreira*a
}

The bioactivity (antioxidant and cytotoxic activities) of the aqueous and methanolic extracts of Arenaria montana L., a plant commonly used in Portuguese folk medicine, was evaluated and compared. Furthermore, the phytochemical composition was determined based on hydrophilic (sugars, organic acids and phenolic compounds) and lipophilic (fatty acids and tocopherols) compounds, in order to valorize this plant material as a functional food/nutraceutical. Fructose, oxalic acid, methyl-luteolin $2^{\prime \prime}-$ $O$-feruloylhexosyl-C-hexoside, $\alpha$-tocopherol, and linoleic acid were the main individual compounds found in A. montana. In general, the aqueous extract showed higher antioxidant and cytotoxic activities than the methanolic extract; the latter showed activity only against HeLa and HepG2 cell lines. Both aqueous and methanolic extracts showed some hepatotoxicity but at higher doses than the ones active for tumor cell lines. Moreover, the aqueous extract of $A$. montana may be used as a functional food or nutraceutical due to the high antioxidant and cytotoxic activities, and due to the presence of bioactive compounds. As far as we know, this is the first report on the phytochemical composition and bioactivity of A. montana.

\section{Introduction}

The study of plants used in folk medicine has progressively increased over the last few decades. ${ }^{1}$ Some of their putative therapeutic benefit arise from a diverse phytochemical composition, which confers them antioxidant potential along with other bioactive properties namely, anticarcinogenic/ antimutagenic, antibacterial, antiviral or anti-inflammatory properties. ${ }^{2,3}$ Among the various biologically active molecules, phenolic compounds are major contributors to the antioxidant activity of those plants. ${ }^{4-10}$ The antioxidant activity of phenolic compounds is influenced by the number and position of phenolic hydroxyls and other substituents, and glycosylation of the molecules. ${ }^{11,12}$ Furthermore, antitumor properties have also been attributed to different phenolic compounds, including flavones. ${ }^{\mathbf{1 3}}$

Other important antioxidant molecules are tocopherols, which are considered as one of the most important antioxidants to combat oxidative stress, because they inhibit the

${ }^{a}$ CIMO-Escola Superior Agrária, Instituto Politécnico de Bragança, Campus de Santa Apolónia, 1172, 5301-855 Bragança, Portugal. E-mail: iferreira@ipb.pt; Fax: +351 273325405; Tel: +351273303219

${ }^{b}$ GIP-USAL, Facultad de Farmacia, Universidad de Salamanca, Campus Miguel de Unamuno, 37007 Salamanca, Spain. E-mail: csb@usal.es; Fax: +34 923 294515; Tel: +34923294537

${ }^{c}$ Centro de Quimica, Universidade do Minho, Campus de Gualtar 4710-057 Braga, Portugal

$\dagger$ Both authors contributed equally. production of peroxyl radicals, protecting cells of oxidative damage to low density lipoproteins, proteins and DNA, and of membrane degeneration due to peroxidation of polyunsaturated fatty acids. ${ }^{\mathbf{1 4}, 15}$ Some organic acids are also excellent antioxidants; for example, ascorbic acid, being a potent reducing agent, has the capacity to reduce the most reactive species of oxygen and nitrogen protecting against lipid peroxidation. ${ }^{16}$ The reducing sugars, due to the same capacity, could also display antioxidant activity. ${ }^{17}$ Different health benefits of polyunsaturated fatty acids (PUFA) have also been described. For example, it was reported that PUFA could be used to sensitize breast cancer cell lines and mammary tumors to anticancer drugs, increasing survival and chemotherapy efficacy. ${ }^{\mathbf{1 8 , 1 9}}$ The mentioned phytochemicals are common in medicinal plants and often responsible for their bioactive effects.

Arenaria montana L. (Mountain sandwort) is an herbaceous plant native to mountainous regions of southwestern Europe, being usually gathered in woodlands. The infusion of the dried plant (stems, leaves and flowers) is used in Portuguese traditional medicine for its anti-inflammatory and diuretic properties. $^{20,21}$ Nevertheless, as far as we know, there are no previous reports on the phytochemical composition of this plant.

The aim of the current study was to characterize the chemical composition of $A$. montana and to assess the antioxidant and cytotoxic properties of their aqueous and methanol extracts. 


\section{Experimental}

\section{Sample}

Arenaria montana L. (Caryophyllaceae) flowers and leafy stems (approximately the upper $15 \mathrm{~cm}$ of the dense clumps produced in spring) are commonly wild gathered in Bragança (Northeastern Portugal). Then these plant materials are dried, prepared in infusion, recommended and used as homemade remedies. ${ }^{21}$ Considering the availability and local consumers' criteria for its medicinal use, the species was collected in full bloom, in spring along paths through the oak trees, in Oleiros, Bragança. A sample for analysis was made by putting together the material from different plants. Voucher specimens are deposited at the Herbarium of the Escola Superior Agrária de Bragança (BRESA). The sample was lyophilized (FreeZone 4.5, Labconco, Kansas City, MO, USA), reduced to a fine dried powder (20 mesh) and mixed to obtain homogeneity.

\section{Standards and reagents}

Acetonitrile $99.9 \%, n$-hexane $95 \%$ and ethyl acetate $99.8 \%$ were of HPLC grade from Fisher Scientific (Lisbon, Portugal). The fatty acids methyl ester (FAME) reference standard mixture 37 (standard 47885-U) was purchased from Sigma (St. Louis, MO, USA), as also were other individual fatty acid isomers, L-ascorbic acid, tocopherols ( $\alpha$-, $\beta$-, $\gamma$-, and $\delta$-isoforms), sugars (D(-)-fructose, $\mathrm{D}(+)$-sucrose, $\mathrm{D}(+)$-glucose, $\mathrm{D}(+)$-trehalose and $\mathrm{D}(+)$-raffinose pentahydrate), trolox (6-hydroxy-2,5,7,8-tetramethylchroman-2carboxylic acid), gallic acid and (+)-catechin standards. Racemic tocol, $50 \mathrm{mg} \mathrm{mL}{ }^{-1}$, was purchased from Matreya (Plesant Gap, PA, USA). 2,2-Diphenyl-1-picrylhydrazyl (DPPH) was obtained from Alfa Aesar (Ward Hill, MA, USA). Fetal bovine serum (FBS), L-glutamine, hank's balanced salt solution (HBSS), trypsinEDTA (ethylenediaminetetraacetic acid), penicillin-streptomycin solution (100 $\mathrm{U} \mathrm{mL}^{-1}$ and $100 \mathrm{mg} \mathrm{mL}^{-1}$, respectively), RPMI-1640 and DMEM media were from Hyclone (Logan, Utah, USA). Acetic acid, ellipticine, sulforhodamine B (SRB), trypan blue, trichloroacetic acid (TCA) and Tris were from Sigma Chemical Co. (Saint Louis, MO, USA). All other chemicals and solvents were of analytical grade and purchased from common sources. Water was treated in a Milli-Q water purification system (TGI Pure Water Systems, Greenville, SC, USA).

\section{Evaluation of bioactivity}

Sample preparation. The methanolic extract was obtained from the lyophilized plant material. The sample (1 g) was extracted by stirring with $25 \mathrm{~mL}$ of methanol $\left(25^{\circ} \mathrm{C}\right.$ at $\left.150 \mathrm{rpm}\right)$ for $1 \mathrm{~h}$ and subsequently filtered through the Whatman no. 4 paper. The residue was then extracted with $25 \mathrm{~mL}$ of methanol $\left(25{ }^{\circ} \mathrm{C}\right.$ at $\left.150 \mathrm{rpm}\right)$ for $1 \mathrm{~h}$. The combined methanolic extracts were evaporated at $40^{\circ} \mathrm{C}$ (rotary evaporator Büchi R-210, Flawil, Switzerland) to dryness.

The aqueous extract (infusion) was also obtained from the lyophilized plant material. The sample $(1 \mathrm{~g})$ was added to 200 $\mathrm{mL}$ of boiling distilled water, left to stand at room temperature for $5 \mathrm{~min}$, and then filtered under reduced pressure. The obtained extract was frozen and lyophilized.
Methanolic and aqueous extracts were redissolved in (i) methanol and water, respectively (final concentration: $2.5 \mathrm{mg}$ $\mathrm{mL}^{-1}$ ) for antioxidant activity evaluation, or (ii) water (final concentration: $8 \mathrm{mg} \mathrm{mL}^{-1}$ ) for cytotoxicity evaluation. The final solutions were further diluted to different concentrations to be submitted for distinct bioactivity evaluation in vitro assays. The results were expressed in (i) $\mathrm{EC}_{50}$ values (sample concentration providing $50 \%$ of antioxidant activity or 0.5 of absorbance in the reducing power assay) for antioxidant activity, or (ii) $\mathrm{GI}_{50}$ values (the sample concentration that inhibited $50 \%$ of the net cell growth) for cytotoxicity. Trolox and ellipticine were used as positive controls in antioxidant and cytotoxic activity evaluation assays, respectively.

Antioxidant activity. DPPH radical-scavenging activity was evaluated by using an ELX800 microplate reader (Bio-Tek Instruments, Inc; Winooski, VT, USA), and calculated as a percentage of DPPH discolouration using the formula: $\left[\left(A_{\mathrm{DPPH}}-A_{\mathrm{S}}\right) / A_{\mathrm{DPPH}}\right] \times$ 100 , where $A_{\mathrm{S}}$ is the absorbance of the solution containing the sample at $515 \mathrm{~nm}$ and $A_{\mathrm{DPPH}}$ is the absorbance of the DPPH solution. Reducing power was evaluated by the capacity to convert $\mathrm{Fe}^{3+}$ into $\mathrm{Fe}^{2+}$, measuring the absorbance at $690 \mathrm{~nm}$ in the microplate reader mentioned above. Inhibition of $\beta$-carotene bleaching was evaluated though the $\beta$-carotene/linoleate assay; the neutralization of linoleate free radicals avoids $\beta$-carotene bleaching, which is measured by the formula: ( $\beta$-carotene absorbance after $2 \mathrm{~h}$ of assay/initial absorbance) $\times 100$. Lipid peroxidation inhibition in porcine (Sus scrofa) brain homogenates was evaluated by the decrease in thiobarbituric acid reactive substances (TBARS); the colour intensity of the malondialdehydethiobarbituric acid (MDA-TBA) was measured by its absorbance at $532 \mathrm{~nm}$; the inhibition ratio (\%) was calculated using the following formula: $[(A-B) / A] \times 100 \%$, where $A$ and $B$ were the absorbance of the control and the sample solution, respectively. ${ }^{22}$

Cytotoxicity for tumor cell lines. Five human tumour cell lines were used: MCF-7 (breast adenocarcinoma), NCI-H460 (non-small cell lung cancer), HCT-15 (colon carcinoma), HeLa (cervical carcinoma) and HepG2 (hepatocellular carcinoma). Cells were routinely maintained as adherent cell cultures in RPMI-1640 medium containing 10\% heat-inactivated FBS (MCF-7, NCI-H460 and HCT-15) and $2 \mathrm{mM}$ glutamine or in DMEM supplemented with 10\% FBS, 2 mM glutamine, $100 \mathrm{U}$ $\mathrm{mL}^{-1}$ penicillin and $100 \mathrm{mg} \mathrm{mL}^{-1}$ streptomycin (HeLa and HepG2 cells), at $37^{\circ} \mathrm{C}$, in a humidified air incubator containing $5 \% \mathrm{CO}_{2}$. Each cell line was plated at an appropriate density (7.5 $\times 10^{3}$ cells per well for MCF-7, NCI-H460 and HCT-15 or $1.0 \times$ $10^{4}$ cells per well for HeLa and HepG2) in 96-well plates and allowed to attach for $24 \mathrm{~h}$. Cells were then treated for $48 \mathrm{~h}$ with various extract concentrations. Following this incubation period, the adherent cells were fixed by adding cold $10 \%$ trichloroacetic acid (TCA, $100 \mu \mathrm{L}$ ) and incubated for $60 \mathrm{~min}$ at $4{ }^{\circ} \mathrm{C}$. Plates were then washed with deionized water and dried; sulforhodamine B solution $(0.1 \%$ in $1 \%$ acetic acid, $100 \mu \mathrm{L})$ was then added to each plate well and incubated for $30 \mathrm{~min}$ at room temperature. Unbound SRB was removed by washing with $1 \%$ acetic acid. Plates were air dried, the bound SRB was solubilised with $10 \mathrm{mM}$ Tris $(200 \mu \mathrm{L})$ and the absorbance was measured at $540 \mathrm{~nm}$ in the microplate reader mentioned above. ${ }^{23}$ 
Hepatotoxicity. A cell culture was prepared from a freshly harvested porcine liver obtained from a local slaughter house, and it was designated as PLP2. Briefly, the liver tissues were rinsed in hank's balanced salt solution containing $100 \mathrm{U} \mathrm{mL}^{-1}$ penicillin, $100 \mu \mathrm{g} \mathrm{mL}{ }^{-1}$ streptomycin and divided into $1 \times 1$ $\mathrm{mm}^{3}$ explants. Some of these explants were placed in $25 \mathrm{~cm}^{2}$ tissue flasks in DMEM medium supplemented with $10 \%$ fetal bovine serum, $2 \mathrm{mM}$ nonessential amino acids, $100 \mathrm{U} \mathrm{mL}^{-1}$ penicillin, and $100 \mathrm{mg} \mathrm{mL}{ }^{-1}$ streptomycin and incubated at $37{ }^{\circ} \mathrm{C}$ with a humidified atmosphere containing $5 \% \mathrm{CO}_{2}$. The medium was changed every two days. Cultivation of the cells was continued with direct monitoring every two to three days using a phase contrast microscope. Before confluence was reached, cells were subcultured and plated in 96-well plates at a density of $1.0 \times 10^{4}$ cells per well, and cultivated in DMEM medium with $10 \% \mathrm{FBS}, 100 \mathrm{U} \mathrm{mL}^{-1}$ penicillin and $100 \mu \mathrm{g} \mathrm{mL}^{-1}$ streptomycin. ${ }^{23}$

\section{Phytochemical composition in hydrophilic compounds}

Sugars. Free sugars were determined by high performance liquid chromatography coupled to a refraction index detector (HPLC-RI), after an extraction procedure previously described by the authors ${ }^{22}$ using melezitose as the internal standard (IS). The equipment consisted of an integrated system with a pump (Knauer, Smartline system 1000, Berlin, Germany), a degasser system (Smartline manager 5000), an auto-sampler (AS-2057 Jasco, Easton, MD, USA) and a RI detector (Knauer Smartline 2300). Data were analysed using Clarity 2.4 Software (DataApex, Prague, Czech Republic). The chromatographic separation was achieved with a Eurospher 100-5 $\mathrm{NH}_{2}$ column $(4.6 \times 250 \mathrm{~mm}, 5$ $\mathrm{mm}$, Knauer) operating at $30{ }^{\circ} \mathrm{C}$ (7971 R Grace oven). The mobile phase was acetonitrile-deionized water, $70: 30(\mathrm{v} / \mathrm{v})$ at a flow rate of $1 \mathrm{~mL} \mathrm{~min}^{-1}$. The compounds were identified by chromatographic comparisons with authentic standards. Quantification was performed using the internal standard method and sugar contents were further expressed in $\mathrm{g}$ per 100 $\mathrm{g}$ of dry weight (dw).

Organic acids. Organic acids were determined following a procedure previously described by the authors. ${ }^{24}$ The analysis was performed using a Shimadzu 20A series UFLC (Shimadzu Coperation, Kyoto, Japan). Separation was achieved using a SphereClone (Phenomenex, Torrance, CA, USA) reverse phase $\mathrm{C}_{18}$ column $(5 \mu \mathrm{m}, 250 \mathrm{~mm} \times 4.6 \mathrm{~mm}$ i.d) thermostatted at $35{ }^{\circ} \mathrm{C}$. The elution was performed with sulphuric acid $3.6 \mathrm{mM}$

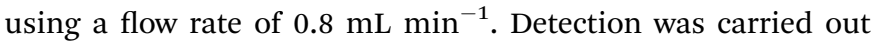
using a DAD, at $215 \mathrm{~nm}$ and $245 \mathrm{~nm}$ (for ascorbic acid) as preferred wavelengths. The organic acids found were quantified by comparison of the area of their peaks recorded at $215 \mathrm{~nm}$ with calibration curves obtained from commercial standards of each compound. The results were expressed in $\mathrm{g}$ per $100 \mathrm{~g}$ of dry weight.

Phenolic compounds. Phenolic compounds were determined by HPLC (Hewlett-Packard 1100, Agilent Technologies, Santa Clara, CA, USA) as previously described by the authors. ${ }^{25}$ Double online detection was carried out using a DAD at $280 \mathrm{~nm}$ and $370 \mathrm{~nm}$ as preferred wavelengths and using a mass spectrometer (API 3200 Qtrap, Applied Biosystems, Darmstadt, Germany) connected to the HPLC system via the DAD cell outlet. The phenolic compounds were characterized according to their UV and mass spectra and retention times, and comparison with authentic standards when available. The phenolic compounds were identified by comparing their retention time, UV-vis and mass spectra with those obtained from standard solutions, when available. Otherwise, peaks were tentatively identified comparing the obtained information with available data reported in the literature. For quantitative analysis, a calibration curve $\left(2.5-100 \mu \mathrm{g} \mathrm{mL}^{-1}\right)$ for each available phenolic standard was constructed based on the UV signal: apigenin 6- $C$ glucoside $\left(y=223.22 x+60.915 ; R^{2}=1\right)$; luteolin 6 - $C$-glucoside $\left(y=508.54 x-152.82 ; R^{2}=0.997\right)$. For the identified phenolic compounds for which a commercial standard was not available, the quantification was performed through the calibration curve of other compounds from the same phenolic group. The results were expressed in $\mathrm{mg}$ per $100 \mathrm{~g}$ of dry weight (dw).

\section{Phytochemical composition in lypophilic compounds}

Fatty acids. Fatty acids were determined by gas-liquid chromatography with a flame ionization detection (GC-FID)/ capillary column as described previously by the authors. ${ }^{22}$ The analysis was carried out with a DANI model GC 1000 instrument equipped with a split/splitless injector, a flame ionization detector (FID at $260{ }^{\circ} \mathrm{C}$ ) and a Macherey-Nagel (Duren, Germany) column (50\% cyanopropyl-methyl-50\% phenylmethylpolysiloxane, $30 \mathrm{~m} \times 0.32 \mathrm{~mm}$ ID $\times 0.25 \mu \mathrm{m} d_{\mathrm{f}}$ ). The oven temperature program is as follows: the initial temperature of the column was $50{ }^{\circ} \mathrm{C}$, held for $2 \mathrm{~min}$, then a $30{ }^{\circ} \mathrm{C} \mathrm{min}{ }^{-1}$ ramp to $125^{\circ} \mathrm{C}, 5^{\circ} \mathrm{C} \mathrm{min}^{-1}$ ramp to $160{ }^{\circ} \mathrm{C}, 20^{\circ} \mathrm{C} \mathrm{min}^{-1}$ ramp to $180{ }^{\circ} \mathrm{C}, 3{ }^{\circ} \mathrm{C} \min ^{-1}$ ramp to $200{ }^{\circ} \mathrm{C}, 20{ }^{\circ} \mathrm{C} \mathrm{min}^{-1}$ ramp to $220^{\circ} \mathrm{C}$ and held for $15 \mathrm{~min}$. The carrier gas (hydrogen) flow-rate was 4.0 $\mathrm{mL} \min ^{-1}$ (0.61 bar), measured at $50{ }^{\circ} \mathrm{C}$. Split injection $(1: 40)$ was carried out at $250{ }^{\circ} \mathrm{C}$. Fatty acid identification was made by comparing the relative retention times of FAME peaks from samples with standards. The results were recorded and processed using the CSW 1.7 Software (DataApex 1.7, Prague, Czech Republic) and expressed in relative percentage of each fatty acid.

Tocopherols. Tocopherols were determined following a procedure previously described by the authors. ${ }^{22}$ Analysis was performed by HPLC (equipment described above), and a fluorescence detector (FP-2020; Jasco, Easton, MD, USA) programmed for excitation at $290 \mathrm{~nm}$ and emission at $330 \mathrm{~nm}$. The chromatographic separation was achieved with a Polyamide II $(250 \times 4.6 \mathrm{~mm})$ normal-phase column from YMC Waters operating at $30^{\circ} \mathrm{C}$. The mobile phase used was a mixture of $n$ hexane and ethyl acetate $(70: 30, \mathrm{v} / \mathrm{v})$ at a flow rate of $1 \mathrm{~mL}$ $\min ^{-1}$, and the injection volume was $20 \mu \mathrm{L}$. The compounds were identified by chromatographic comparisons with authentic standards. Quantification was based on the fluorescence signal response of each standard, using the IS (tocol) method and by using calibration curves obtained from commercial standards of each compound. The results were expressed in $\mathrm{mg}$ per $100 \mathrm{~g}$ of dry weight. 


\section{Statistical analysis}

For each one of the species three samples were used and all the assays were carried out in triplicate. The results are expressed as mean values and standard deviation (SD). The results were analyzed using one-way analysis of variance (ANOVA) followed by Tukey's HSD Test with $\alpha=0.05$. This treatment was carried out using the SPSS v. 18.0 program.

\section{Results and discussion}

\section{Evaluation of antioxidant activity}

The results obtained from the antioxidant activity evaluation of the aqueous and methanolic extracts of $A$. montana are given in Table 1 . The aqueous extract showed higher antioxidant activity than the methanolic extract in all the assays, with the exception of DPPH scavenging activity assay in which both samples showed similar results.

The effects of $A$. montana methanolic and aqueous extracts on the growth of five human tumor cell lines (MCF-7, NCI-H460, HCT-15, HeLa and HepG2), represented as the concentrations that caused $50 \%$ of cell growth inhibition $\left(\mathrm{GI}_{50}\right)$, are also summarized in Table 1 . The aqueous extract showed activity against all the tumor cell lines, while the methanolic extract only presented some activity for HeLa and HepG2 cell lines. In general, it may be concluded that the bioactive compounds involved in growth inhibition of the other cell lines are preferentially extracted in the aqueous preparation. Curiously, HeLa and HepG2 were the most susceptible (lowest $\mathrm{GI}_{50}$ values) cell lines to the aqueous extract. Both the aqueous and methanolic extracts showed some hepatotoxicity but at high doses (332.18 $\mu \mathrm{g} \mathrm{mL} \mathrm{m}^{-1}$ and $350.25 \mu \mathrm{g} \mathrm{mL}{ }^{-1}$, respectively). However, it should be highlighted that at the doses active against tumor cell lines, the aqueous extract did not show hepatotoxicity.

Trolox and ellipticine were used as positive controls in antioxidant and cytotoxic activities evaluation assays, respectively, but the comparison with the samples should be avoided, because they are individual compounds and not mixtures as the studied extracts.

To the best of our knowledge, no reports are available on the bioactivity of the aqueous or methanolic extracts of the aforementioned plant.

\section{Composition in hydrophilic compounds}

The chemical composition of the samples in sugars and organic acids was also analyzed and the results are shown in Table 2. The sugars found were fructose, glucose, sucrose trehalose and raffinose, fructose being the most abundant; as a reducing sugar it has antioxidant capacity.

Oxalic, quinic, malic, ascorbic, citric, succinic and fumaric acids were also identified and quantified (Table 2), oxalic and malic acids being the most abundant organic acids. Some of these acids (e.g., ascorbic and citric acids) have been reported as having antioxidant capacity and health benefits. ${ }^{26,27}$ Oppositely, several studies indicate that oxalic acid causes acute oxalate nephropathy and neurotoxicity in humans and animals. ${ }^{28}$

Ten phenolic compounds were identified in the methanolic extract of $A$. montana (flowers and leafy stems) being all of them flavone derivatives. The HPLC phenolic profile recorded at 370

Table 2 Composition in hydrophilic compounds of wild Arenaria montana. ${ }^{a}$

\begin{tabular}{lcll}
\hline Free sugars & g per $100 \mathrm{~g} \mathrm{dw}$ & Organic acids & g per $100 \mathrm{~g} \mathrm{dw}$ \\
\hline Fructose & $5.46 \pm 0.53$ & Oxalic acid & $1.93 \pm 0.09$ \\
Glucose & $2.05 \pm 0.33$ & Quinic acid & $0.06 \pm 0.00$ \\
Sucrose & $1.41 \pm 0.32$ & Malic acid & $1.48 \pm 0.00$ \\
Trehalose & $0.80 \pm 0.01$ & Ascorbic acid & $0.02 \pm 0.00$ \\
Raffinose & $0.43 \pm 0.00$ & Citric acid & $0.30 \pm 0.03$ \\
Total sugars & $10.15 \pm 0.99$ & Succinic acid & $0.28 \pm 0.03$ \\
& & Fumaric acid & $0.01 \pm 0.00$ \\
& & Total organic acids & $4.07 \pm 0.08$
\end{tabular}

${ }^{a} \mathrm{dw}$ - dry weight.

Table 1 Bioactivity of Arenaria montana methanolic and aqueous extracts

\begin{tabular}{|c|c|c|c|}
\hline \multicolumn{4}{|l|}{ Antioxidant activity } \\
\hline DPPH scavenging activity $\left(\mathrm{EC}_{50}, \mathrm{mg} \mathrm{mL}^{-1}\right)$ & $0.90 \pm 0.01^{\mathrm{a}}$ & $0.93 \pm 0.02^{\mathrm{a}}$ & $0.04 \pm 0.00$ \\
\hline$\beta$-Carotene bleaching inhibition $\left(\mathrm{EC}_{50}, \mathrm{mg} \mathrm{mL}^{-1}\right)$ & $6.25 \pm 0.31^{\mathrm{a}}$ & $1.71 \pm 0.02^{\mathrm{b}}$ & $0.003 \pm 0.00$ \\
\hline TBARS inhibition $\left(\mathrm{EC}_{50}, \mathrm{mg} \mathrm{mL}^{-1}\right)$ & $0.90 \pm 0.08^{\mathrm{a}}$ & $0.20 \pm 0.02^{\mathrm{b}}$ & $0.004 \pm 0.00$ \\
\hline NCI-H460 (non-small cell lung cancer) $\left(\mathrm{GI}_{50}, \mu \mathrm{g} \mathrm{mL}^{-1}\right)$ & $>400^{\mathrm{a}}$ & $231.08 \pm 5.86^{\mathrm{b}}$ & $1.42 \pm 0.00$ \\
\hline HCT-15 (colon carcinoma) $\left(\mathrm{GI}_{50}, \mu \mathrm{g} \mathrm{mL} \mathrm{m}^{-1}\right)$ & $>400^{\mathrm{a}}$ & $183.51 \pm 15.54^{\mathrm{b}}$ & $1.91 \pm 0.06$ \\
\hline HeLa (cervical carcinoma) $\left(\mathrm{GI}_{50}, \mu \mathrm{g} \mathrm{mL}^{-1}\right)$ & $329.46 \pm 12.46^{\mathrm{a}}$ & $80.21 \pm 6.29^{\mathrm{b}}$ & $1.14 \pm 0.21$ \\
\hline HepG2 (hepatocellular carcinoma) $\left(\mathrm{GI}_{50}, \mu \mathrm{g} \mathrm{mL} \mathrm{L}^{-1}\right)$ & $308.68 \pm 13.25^{\mathrm{a}}$ & $58.57 \pm 6.59^{\mathrm{b}}$ & $3.22 \pm 0.67$ \\
\hline Hepatotoxicity & $350.25 \pm 5.70^{\mathrm{a}}$ & $332.18 \pm 3.61^{\mathrm{b}}$ & $2.06 \pm 0.03$ \\
\hline
\end{tabular}

${ }^{a}$ Trolox and ellipticine for antioxidant and cytotoxic activity assays, respectively. $\mathrm{EC}_{50}$ values correspond to the sample concentration achieving $50 \%$ of antioxidant activity or 0.5 of absorbance in reducing power assay. $\mathrm{GI}_{50}$ values correspond to the sample concentration achieving $50 \%$ of growth inhibition in human tumour cell lines or in liver primary culture PLP2. In each row different letters mean significant differences $(p<0.05)$. 


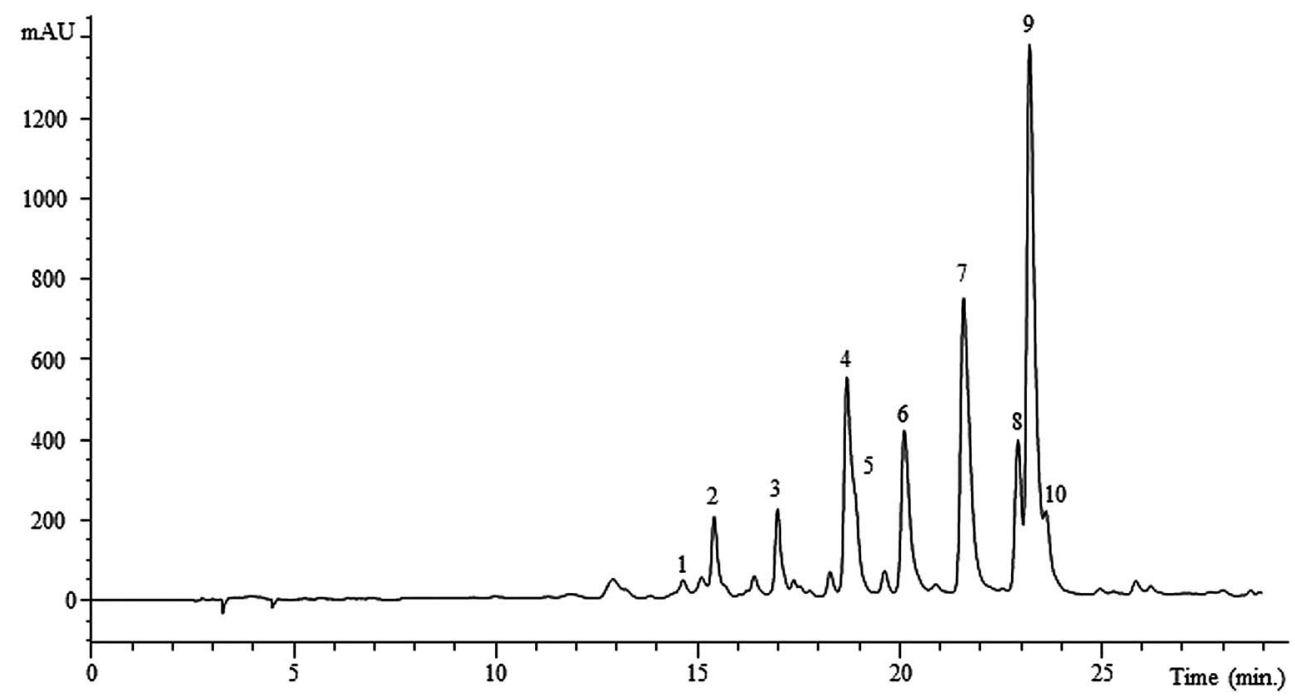

Fig. 1 HPLC phenolic profile of wild Arenaria montana, obtained at $370 \mathrm{~nm}$.

Table 3 Retention time $\left(R_{\mathrm{t}}\right)$, wavelengths of maximum absorption in the UV-vis region $\left(\lambda_{\max }\right)$, pseudomolecular and $\mathrm{MS}^{2}$ fragment ions (in brackets, relative abundances), tentative identification and quantification of phenolic compounds in wild Arenaria montana

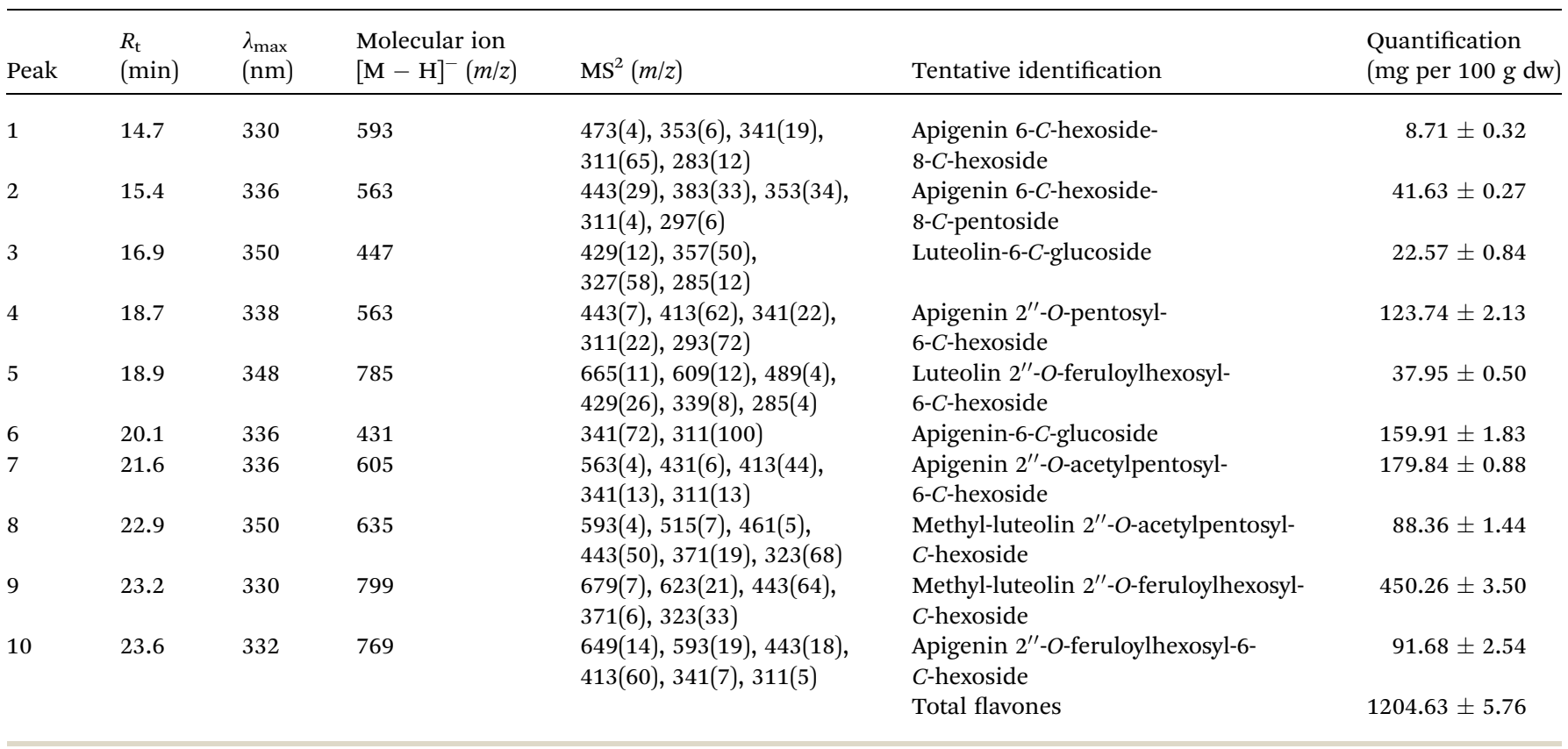

$\mathrm{nm}$ is shown in Fig. 1, and peak characteristics, identities and quantification are presented in Table 3.

Luteolin-6- $C$-glucoside (peak 3 ) and apigenin 6- $C$-glucoside (peak 6) were positively identified according to their retention, mass and UV-vis characteristics by comparison with commercial standards.

Peaks 2, 4 and 7 presented similar UV spectra to peak 6 with a $\lambda_{\max }$ at $336-338 \mathrm{~nm}$, suggesting that may derive from apigenin. All these peaks showed fragments ions at $m / z 311$ and 341, corresponding to the aglycone (apigenin) $+41 \mathrm{mu}$ and $+71 \mathrm{mu}$, respectively, that are characteristic of $C$-glycosylated flavones. ${ }^{29}$ Peaks 2 and 4 had the same pseudomolecular ion $[\mathrm{M}-\mathrm{H}]^{-}$at $\mathrm{m} / z 563$ pointing to apigenin bearing pentose and hexose sugar substituents, but yielded different $\mathrm{MS}^{2}$ fragment ions. According to Ferreres et al.,$^{29}$ the ions aglycone $+83 \mathrm{mu}$ and aglycone + $113 \mathrm{mu}$ would typify di-C-glycosylated flavones. Thus, the observation of the ions at $m / z 383(\mathrm{agl}+113)$ and $353(\mathrm{agl}+83)$ in the case of peak 2 would indicate that both sugars are $C$ attached, which is supported by the losses of $-120 \mathrm{mu}$ (ion at $\mathrm{m} / \mathrm{z} 443),-180 \mathrm{mu}(90+90 ; \mathrm{m} / \mathrm{z}$ at 383$)$, and $210 \mathrm{mu}(120+90$; $\mathrm{m} / z$ at 353 ), characteristic of $C$-glycosylated flavones. ${ }^{30}$ The loss of $-120 \mathrm{mu}$ is typical of $C$-attached hexoses, whereas that of $-90 \mathrm{mu}$ is observed for $C$-attached pentoses and it is also usual in the case of 6-C-hexoses but less common in the case of 


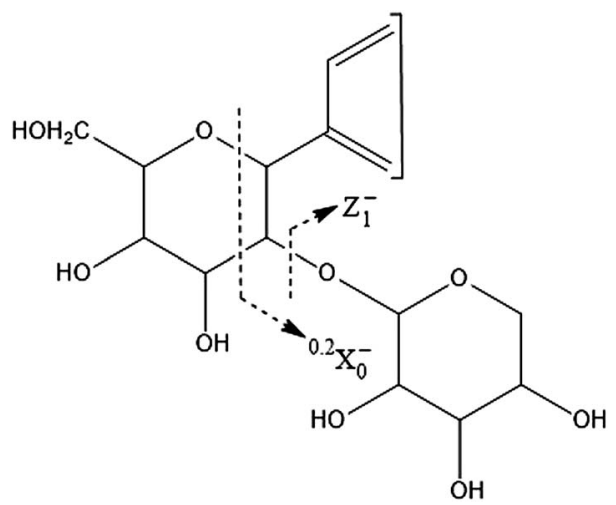

Fig. 2 Fragmentation of $x^{\prime \prime}$-glycosyl-C-glycosylflavones (adapted from Ferreres et al. $^{29}$ ).

8-C-hexoses. ${ }^{31}$ These observations allowed the tentative identification of peak 2 as apigenin $6-C$-hexoside-8- $C$-pentoside.

The fragmentation of peak 4 would be more coherent with an $O, C$-diglycoside. The loss of $-120 \mathrm{mu}$ leading to the ion at $\mathrm{m} / \mathrm{z}$ $443\left({ }^{0,2} \mathrm{X}_{0}^{-}\right.$in Fig. 2) supported the presence of a $C$-attached hexose, while the absence of an ion $[(\mathrm{M}-\mathrm{H})-90]^{-}$pointed to a 6- $C$ attachment. The lack of an ion $[(\mathrm{M}-\mathrm{H})-132]^{-}$from the loss of the pentosyl residue suggested that this sugar was not linked to the aglycone but to the other sugar; this was confirmed by the presence of an abundant $[(\mathrm{M}-\mathrm{H})-150]^{-}$ion $\left(\mathrm{Z}_{1}{ }^{-}\right.$in Fig. 2) at $\mathrm{m} / \mathrm{z} 413$, which according to Ferreres et al. ${ }^{29}$ would be characteristic of an $O$-attached pentose on the $C$-glycosylating hexose. The $O$-glycosylation should not take place in the positions $6^{\prime \prime}, 4^{\prime \prime}$ or $3^{\prime \prime}$ of the hexose, otherwise the fragment $[(\mathrm{M}-\mathrm{H})$ $-120]^{-}$would not be produced. Finally, the ion at $\mathrm{m} / \mathrm{z} 293$ would result from the fragment at $\mathrm{m} / \mathrm{z} 413$ by further loss of a fragment of $120 \mathrm{mu}$ (partial loss of the $C$-attached hexose). All in all, peak 4 could be tentatively identified as apigenin $2^{\prime \prime}-O$ pentosyl-6-C-hexoside.

Peak $7\left([\mathrm{M}-\mathrm{H}]^{-}\right.$at $\left.m / z 605\right)$ was 42 mu greater than peak 4 and showed a similar fragmentation pattern, so that it can be assigned to an acetyl derivative of peak 4 . The observation of an abundant ion at $m / z 413\left([(\mathrm{M}-\mathrm{H})-42-150]^{-}\right)$from the loss of the pentose after release of the acetyl residue would confirm that this sugar was $O$-linked to the $C$-hexose. The observation of an ion at $m / z 431\left([(\mathrm{M}-\mathrm{H})-42-132]^{-}\right)$might indicate that the acetyl moiety is attached to the pentose. Further losses of $-120 \mathrm{mu}$ and $-90 \mathrm{mu}$ from that ion suggested that the hexose was 6-C-attached. Thus, the peak was tentatively assigned as apigenin $2^{\prime \prime}$-O-acetylpentosyl-6- $C$-hexoside.

Peaks 1 and 10 would also derive from apigenin owing to the presence of the fragments at $\mathrm{m} / \mathrm{z} 311$ and 341. In the case of peak $1\left([\mathrm{M}-\mathrm{H}]^{-}\right.$at $\left.\mathrm{m} / \mathrm{z} 593\right)$ the observation of the ions at $\mathrm{m} / \mathrm{z}$ 473 and 353 from two consecutive losses of -120 mu would point to a di-C-hexosyl derivative, so that it could be tentatively associated with apigenin 6-C-hexoside-8- $C$-hexoside.

Peak $10\left([\mathrm{M}-\mathrm{H}]^{-}\right.$at $\left.m / z 769\right)$ had a mass $176 \mathrm{mu}$ greater than apigenin di-hexoside suggesting acylation with ferulic acid, which is coherent with its delayed elution. The cleavage of the feruloyl residue yielded the ion at $m / z 593$, which would give rise to the formation of the abundant ion at $\mathrm{m} / \mathrm{z} 413$ by loss of a fragment of $180 \mathrm{mu}$, which, according to Ferreres et al. ${ }^{29}$ would be characteristic of an $O, C$-dihexoside. On the other hand, the loss of $-120 \mathrm{mu}$ to produce the ion at $\mathrm{m} / \mathrm{z} 649$ confirmed the existence of a hexose $C$-attached to the aglycone, and also that the feruloyl residue was linked to the second $O$-attached hexose. In similarity with the other apigenin $O, C$-diglycosides observed in the sample, a 6-C attachment might be supposed. Thus, peak 10 was tentatively assigned as apigenin $2^{\prime \prime}$-O-feruloylhexosyl-6$C$-hexoside.

The fragmentation pattern of peak $5\left([\mathrm{M}-\mathrm{H}]^{-}\right.$at $\left.m / z 769\right)$ would also be coherent with a structure similar to peak 10 although having luteolin as the aglycone. Thus, the losses of $-120 \mathrm{mu}$ (ion at $\mathrm{m} / \mathrm{z} 489$ ) and $-176 \mathrm{mu}$ (ion at $\mathrm{m} / \mathrm{z} 609$ ), and further $-180 \mathrm{mu}$ (ion at $\mathrm{m} / \mathrm{z} 429$ ) would point to a $O, C$-dihexoside. The fragment at $m / z 489$ (loss of $-120 \mathrm{mu}$ from the ion at $\mathrm{m} / \mathrm{z} 609$ ) would confirm the presence of the $C$-attached hexose, and the ion at $m / z 339$ (loss of $-90 \mathrm{mu}$ from the ion at $\mathrm{m} / \mathrm{z} 429$ ) would suggest a $6 \mathrm{C}$ attachment. Thus, the peak was tentatively identified as luteolin $2^{\prime \prime}$-O-feruloylhexosyl-6- $C$-hexoside.

A pseudomolecular ion of peak $9\left([\mathrm{M}-\mathrm{H}]^{-}\right.$at $m / z$ 799) was 14 mu greater than peak 5 and showed a similar fragmentation pattern, with characteristic product ions resulting from the losses of fragments of $120 \mathrm{mu}$ (ion at $\mathrm{m} / \mathrm{z} 679$ ), $176 \mathrm{mu}$ (ion at $\mathrm{m} /$ $z 623$ ), $176+180 \mathrm{mu}$ (ion at $\mathrm{m} / \mathrm{z} 609$ ) and $176+180+120 \mathrm{mu}$ (ion at $m / z$ 323). The observation of fragments at $m / z 371$ (aglycone + $71 \mathrm{mu}$ ) and 323 (aglycone $+41-18 \mathrm{mu}$ ) would support the presence of methyl-luteolin as the aglycone. ${ }^{29}$ Therefore, the compound might be tentatively assigned as methyl-luteolin $2^{\prime \prime}$-O-feruloylhexosyl- $C$-hexoside.

Finally, peak 8 presented a pseudomolecular ion $[\mathrm{M}-\mathrm{H}]^{-}$at $\mathrm{m} / \mathrm{z} 635$ and fragment ions at $m / z 593(-42 \mathrm{mu}), 515(-120 \mathrm{mu})$, indicating the presence of an acetyl residue and a $C$-attached hexose. The abundant ion at $\mathrm{m} / \mathrm{z} 443$ by loss of a fragment of 150 $\mathrm{mu}$ from the ion at $\mathrm{m} / \mathrm{z} 515$ would indicate the presence of an $O$-attached pentose on the $C$-glycosylating hexose. ${ }^{29}$ The fragment at $\mathrm{m} / \mathrm{z} 461$ would result from the loss of the pentosyl residue $(-132 \mathrm{mu})$ from the ion at $\mathrm{m} / \mathrm{z} 515$, and the ions at $\mathrm{m} / \mathrm{z}$ 371 and 323 would also support methyl-luteolin as the aglycone. Thus, the compound was tentatively identified as methylluteolin $2^{\prime \prime}$-O-acetylpentosyl- $C$-hexoside.

Methyl-luteolin $2^{\prime \prime}$-O-feruloylhexosyl-C-hexoside was the main flavone found ( $450.26 \mathrm{mg}$ per $100 \mathrm{~g} \mathrm{dw}$ ) in A. montana (Table 3), the total amount of flavones being $1204.63 \mathrm{mg}$ per 100 $\mathrm{g} d w$. As far as we know, there are no data regarding the phenolic composition in this plant, and thus these values cannot be compared to the literature. It should also be highlighted that little is known about phenolic compound bioactive forms in vivo (achievable concentrations in the circulation after ingestion as well as the possibility of metabolism) and the mechanisms by which they may contribute toward disease prevention. ${ }^{32}$

\section{Composition in lipophilic compounds}

The results of lipophilic compounds (fatty acids and tocopherols) are shown in Table 4 . Up to 28 fatty acids were identified 
Table 4 Chemical composition in lipophilic compounds of wild Arenaria montana ${ }^{a}$

\begin{tabular}{|c|c|c|c|}
\hline Fatty acids & $\begin{array}{l}\text { Relative } \\
\text { percentage }\end{array}$ & Fatty acids & $\begin{array}{l}\text { Relative } \\
\text { percentage }\end{array}$ \\
\hline C6:0 & $1.32 \pm 0.01$ & C18:3n 3 & $15.94 \pm 0.14$ \\
\hline $\mathrm{C} 8: 0$ & $0.30 \pm 0.01$ & $\mathrm{C} 20: 0$ & $3.84 \pm 0.67$ \\
\hline C10:0 & $0.12 \pm 0.03$ & C20:1 & $0.52 \pm 0.29$ \\
\hline C12:0 & $0.66 \pm 0.21$ & $\mathrm{C} 20: 2$ & $0.70 \pm 0.09$ \\
\hline C13:0 & $0.15 \pm 0.00$ & C20:3n6 & $1.99 \pm 0.04$ \\
\hline C14:0 & $1.37 \pm 0.27$ & C20:4n6 & $1.75 \pm 0.06$ \\
\hline C14:1 & $0.55 \pm 0.04$ & $\begin{array}{l}\text { C20:3n3 + } \\
\text { C21:0 }\end{array}$ & $0.50 \pm 0.00$ \\
\hline C15:0 & $0.93 \pm 0.17$ & $\mathrm{C} 20: 5 \mathrm{n} 3$ & $0.31 \pm 0.08$ \\
\hline C15:1 & $0.09 \pm 0.00$ & $\mathrm{C} 22: 0$ & $3.58 \pm 0.23$ \\
\hline C16:0 & $22.18 \pm 0.40$ & C22:1n9 & $0.08 \pm 0.00$ \\
\hline C16:1 & $0.36 \pm 0.18$ & C23:0 & $0.20 \pm 0.06$ \\
\hline C17:0 & $0.68 \pm 0.03$ & C24:0 & $3.45 \pm 0.46$ \\
\hline C18:0 & $4.38 \pm 0.10$ & SFA & $43.16 \pm 0.38$ \\
\hline C18:1n9 & $8.57 \pm 0.28$ & MUFA & $10.16 \pm 0.43$ \\
\hline C18:2n6 & $23.39 \pm 0.66$ & PUFA & $46.68 \pm 0.82$ \\
\hline C18:3n6 & $2.11 \pm 0.02$ & & \\
\hline Tocopherols & $\mathrm{mg}$ per $100 \mathrm{~g} \mathrm{dw}$ & & \\
\hline$\alpha$-Tocopherol & $1.22 \pm 0.21$ & & \\
\hline$\gamma$-Tocopherol & $0.23 \pm 0.02$ & & \\
\hline$\delta$-Tocopherol & $0.84 \pm 0.08$ & & \\
\hline $\begin{array}{l}\text { Total } \\
\text { tocopherols }\end{array}$ & $2.29 \pm 0.31$ & & \\
\hline
\end{tabular}

and quantified. Polyunsaturated fatty acids (PUFA) predominated over saturated fatty acids (SFA) and monounsaturated fatty acids (MUFA). Linoleic (C18:2n6) acid was the major fatty acid and contributes to the high levels of PUFA observed. The interest of linoleic acid has increased over time, since it is an essential fatty acid for human development and plays an active role in good general health. ${ }^{33}$ Among others, it has been shown to have a role on the prevention of cancer diseases. ${ }^{34}$ PUFA, besides being endogenous mediators of cell signaling and being involved in regulating gene expression, are also precursors of eicosanoids, such as prostaglandins and leukotrienes, as well as docosanoids as protectins or resolvins. ${ }^{33}$

$\alpha$-Tocopherol was the most abundant tocopherol in A. montana, which is also found in the isoforms $\gamma$ - and $\delta$-; Table 4 . Tocopherols are very important natural antioxidants and can be used to delay rancidity in fatty materials in manufactured foods; they may also reduce the effects of aging and help to prevent oxidative stress-related diseases such as cancer, neurodegenerative and heart diseases. ${ }^{35,36}$

\section{Conclusion}

In summary, bioactive phytochemicals such as phenolic compounds and tocopherols were identified and quantified in A. montana, as also omega-3 and omega- 6 families, constituting another important class of phytochemicals due to their generalised beneficial health effects. The aqueous extract revealed higher antioxidant and cytotoxic activities than the methanolic extract. Therefore, the aqueous extract of A. montana may be used as a functional food, due to the high antioxidant activity, and as a nutraceutical, by presenting bioactive compounds, such as flavones and tocopherols, that can be used as cytotoxic agents. Moreover, this study supports the documented medicinal effect of this species and opens up the possibilities of food and pharmaceutical applications.

\section{Competing interests}

The authors declare no competing financial interest.

\section{Acknowledgements}

The authors are grateful to Fundação para a Ciência e a Tecnologia (FCT, Portugal) for financial support to CIMO (strategic project PEst-OE/AGR/UI0690/2011), REQUIMTE (PEst-C/EQB/ LA0006/2011), M.I. Dias (SFRH/BD/84485/2012 grant), R.C. Calhelha (SFRH/BPD/68344/2010 grant) and L. Barros (contract under "Programa Compromisso com Ciência-2008"). The GIPUSAL is financially supported by the Spanish Government through the Consolider-Ingenio 2010 Programme (FUN-CFOOD, CSD2007-00063). M. Dueñas thanks to the Programa Ramón y Cajal for a contract.

\section{References}

1 G. Bulut and E. Tuzlaci, J. Ethnopharmacol., 2013, 149, 633647.

2 K. T. Chung, T. Y. Wong, Y. W. Huang and Y. Lin, Crit. Rev. Food Sci. Nutr., 1998, 38, 421-464.

3 H. Tapiero, K. D. Tew, N. Ba and G. Mathé, Biomed. Pharmacother., 2002, 56, 200-207.

4 C. A. Rice-Evans, N. J. Miller and G. Paganga, Free Radical Biol. Med., 1996, 20, 933-956.

5 S. Dragland, H. Senoo, K. Wake, K. Holte and R. Blomhoff, J. Nutr., 2003, 133, 1286-1290.

6 Y. Z. Cai, Q. Luo, M. Sun and H. Corke, Life Sci., 2004, 74, 2157-2184.

7 L. Sha, L. Shu-Ke, G. Ren-You, S. Feng-Lin, K. Lei and L. HuaBin, Ind. Crop. Prod., 2013, 51, 289-298.

8 K. Kalantar-Zadeh, G. H. Leeb and G. Block, Med. Hypotheses, 2004, 62, 280-290.

9 S. Schaffer and B. Halliwell, Genes Nutr., 2012, 7, 99-109.

10 V. Castel, O. Andrich, F. M. Netto, L. G. Santiago and C. R. Carrara, J. Food Eng., 2014, 122, 62-67.

11 T. Yokozawa, C. P. Chen, E. Dong, T. Tanaka, G.-I. Nonaka and I. Nishioko, Biochem. Pharmacol., 1998, 56, 213-222.

12 Y.-Z. Cai, M. Sun, J. Xing, Q. Luo and H. Corke, Life Sci., 2006, 78, 2872-2888.

13 M. Carocho and I. C. F. R. Ferreira, Anti-Cancer Agents Med. Chem., 2013, 13, 1236-1258.

14 Y. Z. Fang, S. Yang and G. Wu, Nutrition, 2002, 18, 872-879. 15 T. S. Kim, E. A. Decker and J. Lee, Food Chem., 2012, 133, 6875.

16 B. Halliwell, Nutr. Rev., 2012, 70, 257-265. 
17 I. Spasojević, A. Bajić, K. Jovanović, M. Spasić and P. Andjus, Carbohydr. Res., 2009, 344, 1676-1681.

18 N. Hajjaji and P. Bougnoux, Cancer Treat. Rev., 2013, 39, 473488.

19 R. Wannous, E. Bon, K. Mahéoa, C. Goupille, J. Chamouton, P. Bougnoux, S. Roger, P. Besson and S. Chevalier, Biochim. Biophys. Acta, 2013, 1831, 1618-1625.

20 G. Timité, A.-C. Mitaine-Offer, T. Miyamoto, C. Tanaka, J.-F. Mirjolet, O. Duchamp and M.-A. Lacaille-Dubois, Phytochemicals, 2011, 72, 503-507.

21 A. M. Carvalho and R. Morales, in Ethnobotany in the New Europe: People, ed. M. Pardo de Santayana, A. Pieroni and R. Puri, Berghahn Books, Oxford, UK, 2nd edn, 2013, pp. 147-171.

22 J. Pinela, L. Barros, A. M. Carvalho and I. C. F. R. Ferreira, Food Chem. Toxicol., 2011, 49, 2983-2989.

23 R. Guimarães, L. Barros, M. Dueñas, R. C. Calhelha, A. M. Carvalho, C. Santos-Buelga, M. J. R. P. Queiroz and I. C. F. R. Ferreira, Food Chem., 2013, 136, 718-725.

24 L. Barros, C. Pereira and I. C. F. R. Ferreira, Food Anal. Method., 2013, 6, 309-316.

25 L. Barros, M. Dueñas, A. M. Carvalho, I. C. F. R. Ferreira and C. Santos-Buelga, Food Chem. Toxicol., 2012, 50, 15761582.
26 A. R. Hraš, M. Hadolin, Ž. Knez and D. Bauman, Food Chem., 2000, 71, 229-233.

27 H. Kim, S. Baea, Y. Kima, C.-H. Cho, S. J. Kim, Y.-J. Kim, S.-P. Lee, H.-R. Kim, Y.-I. Hwang, J. S. Kanga and W. J. Lee, Free Radicals Biol. Med., 2013, 65, 573-583.

28 H.-C. Fang, C.-L. Chen, P.-T. Lee, C.-Y. Hsu, C.-J. Tseng, P.-J. Lu, S.-L. Lai, H.-M. Chung and K.-J. Chou, Food Chem. Toxicol., 2007, 45, 1764-1769.

29 F. Ferreres, A. Gil-Izquierdo, P. B. Andrade, P. Valentão and F. A. Tomás-Barberán, J. Chromatogr. A, 2007, 1161, 214-223.

30 F. Cuyckens and M. Claeys, J. Mass Spectrom., 2004, 39, 1-15.

31 F. Ferreres, B. M. Silva, P. B. Andrade, R. M. Seabra and M. A. Ferreira, Phytochem. Anal., 2003, 14, 352-390.

32 A. R. Rechner, G. Kuhnle, P. Bremner, G. P. Hubbard, K. P. Moore and C. A. Rice-Evans, Free Radicals Biol. Med., 2002, 33, 220-235.

33 B. Choque, D. Catheline, V. Rioux and P. Legrand, Biochimie, 2014, 96, 14-21.

34 J. Whelan, Prostaglandins, Leukotrienes Essent. Fatty Acids, 2008, 79, 165-167.

35 B. Halliwell, Trends Biochem. Sci., 1999, 24, 255-259.

36 V. E. Kagan, A. I. Kuzmenkoa, A. A. Shvedovae, E. R. Kisine, R. Lia, I. Martina, P. J. Quinna, V. A. Tyurina, Y. Y. Tyurinaa and J. C. Yalowich, Biochim. Biophys. Acta, 2003, 1620, 72-84. 